no apparent increase in the annual proportions of patients requiring medication.

Patients in the prescribed group were more likely to have longer admissions. Contributory factors included period of assessment of whether medication was effective, changes of agent and non-compliance due to family reluctance to consent or as the result of unpleasant sideeffects. Patients in the group were far more likely to return for a subsequent episode, which is in keeping with the nature of psychotic illness. The average one-year age difference, and the increased proportion of males are consistent with established knowledge of the onset of psychotic illness.

During the design and implementation of the study, we were constrained by several factors which limited the scope of the survey. A few sets of case notes were unavailable because the patient's care had been transferred outside of the district. Of those case notes which were available, prescription cards were not always present or complete. A more fundamental problem was achieving a useful quantification of the use of medication. There was a great variation in the dosages, lengths of prescription, combinations of agents and changes from one agent to another. Where changes were made, it was not always clear why this had been done.

Within the limited scope of this survey, considerable interest was generated. Awareness was raised about the need for accurate note keeping, and two initiatives started: the explicit and systematic recording of medication changes, and the further development of multi-language drug information for patients and carers.

\section{Acknowledgements}

We wish to thank Brenda Wallace for her assistance in locating case notes and the staff at Linton House for their cooperation.

\section{References}

LOWE. K., SMITH, H. \& CLARK, A. (1996) Neuroleptic prescribing in an adolescent psychiatric in-patient unit. Psychiatric Bulletin, 20, 538-540.

WORLD HEALTH ORGanization (1978) Mental Disorders: Glossary and Guide to their Classification in Accordance with the Ninth Revision of the International Classification of Diseases (ICD-9). Geneva: WHO.

*Peter McLoughlin, Specialist Registrar in Child and Adolescent Psychiatry, 123 Little Horton Lane, Bradford BD5 OHT; Jean Phillips, Staff Nurse, Linton House, High Royds Hospital, Menston, Ilkley: David West, Research and Development Information Manager, R\&D Directorate, Leeds; and Dorothea Holman. Consultant Child and Adolescent Psychiatrist, Linton House, High Royds Hospital, Menston. Ilkley

*Correspondence

\title{
Optimising neuroleptic treatment for psychotic illness
}

\author{
Geoffrey Searle
}

The release of the antipsychotic agents risperidone, sertindole and olanzepine forces difficult choices upon clinicians. The new compounds are betfer tolerated than neuroleptics, expensive and their long-term sideeffects unknown. These choices can be made easier by the dose and side-effect minimiscation procedure set out below, which aims to produce the greatest benefit and least harm from conventional neuroleptics.
Standard reviews of dosages recommended from research into effectiveness are all flawed from a clinician's viewpoint as the judgments are population based, usually focused on one drug and do not address the wide differences between individuals' sensitivity to neuroleptics (e.g. haloperidol; Hilton et al, 1996). Similarly, psychiatric textbooks and the consensus statement of the 
Royal College of Psychiatrists do not give advice on how to judge which drug to use and in what amount although the consensus statement makes it clear that doses above British National Formulary maximum advisory dose limits are unacceptable unless closely monitored (Thompson, 1994). That sensitivity to medication varies during the course of the disease seems to have been ignored, although it is clinically often observed that acutely psychotic patients (a group relatively little researched) can be remarkably tolerant of high doses of neuroleptic drugs. In clinical practice one cannot accept dropout or treatment failure which are acceptable outcomes in trials using limited dose ranges. The method used by many of the clinicians who trained me (and I assume many readers) was to increase a neuroleptic until the patient began to improve. the British National Formulary dose limit was reached, their sedation was satisfactory or movement disorders could not be contained with anticholinergic medication.

The idea of treating patients with neuroleptic agents only to the point at which they develop extrapyramidal symptoms is not new (older colleagues tell me). In recent years, McEvoy has published papers describing a radical approach to dose-finding based on the concept of "neuroleptic threshold', and his research (McEvoy et al, 1991) seems to demonstrate no extra antipsychotic effect from treating people with schizophrenia with haloperidol doses beyond those producing slight stiffness and cogwheel rigidity which is coherent with the in vitro findings of Farde et al, 1992. Transforming McEvoy's research into a widely applicable algorithm requires some thought as one must allow the use of various compounds which have different half-lives and various sedative proper- ties (Table 1), and allow that akathisia may be the movement disorder developed by the patient.

\section{Treatment}

The flow chart (Fig. 1) deliberately does not assume that the patient is drug naive, but to start by explaining to the patient what you will be doing is essential. Those patients without previous experience of neuroleptics will need to be warned what side-effects to look for and to be reassured that the dosage will be cut if they occur. Some out-patients can detect their own 'neuroleptic threshold', speeding their treatment considerably. Should you adopt this model you will rapidly discover that in some patients as the psychotic symptoms recede the neuroleptic threshold rapidly falls requiring swift cuts in medication dosage. Anticholinergic medication is often required at this stage but delaying morning doses allows side-effects to be examined to determine if the neuroleptic threshold has been regained. Similarly tolerance to neuroleptics seems to rise during relapses. Knowledge of these two processes can be shared with patients and this can ease the process of increasing the medication of sceptical patients with psychotic illness.

Haloperidol and chlorpromazine are widely used and have high British National Formulary limits, trifluoperazine has no maximum advisory British National Formulary limit. Thioridazine is problematic as its inherent anticholinergic properties make definition of the neuroleptic threshold difficult. The rate of increase in dosage is determined by the clinical situation and the halflife of the neuroleptic, equilibrium is reached in five half-lives of the chosen compound. Increased

Table 1. Antipsychotic drugs

\begin{tabular}{llll}
\hline & $\begin{array}{l}\text { Average half-life } \\
\text { (hours) }\end{array}$ & $\begin{array}{l}\text { Average time to } \\
\text { steady state (days) }\end{array}$ & Sedation \\
\hline $\begin{array}{llll}\text { Phenothiazines } \\
\text { Chlorpromazine }\end{array}$ & $12-36$ & $2.5-7.5$ & +++ \\
$\begin{array}{l}\text { Fluphenazine } \\
\text { Thioridazine }\end{array}$ & 33 & 7 & ++ \\
Trifluoperazine & 10 & $2-2.5$ & + \\
$\begin{array}{l}\text { Butyrophenones } \\
\text { Droperidol }\end{array}$ & $8-12$ & & + \\
Haloperidol & & 1 & + \\
Others & $2-3$ & $4-8$ & + \\
Flupenthixol & $18-36$ & & + \\
Zuclopenthixol & & 7 & + \\
Pimozide & 35 & 4 & + \\
Risperidone & 20 & 12 & $+?$ \\
Sulpiride & $55-150$ & 5 & + \\
Clozapine & 24 & 2.5 & ++ \\
\hline
\end{tabular}




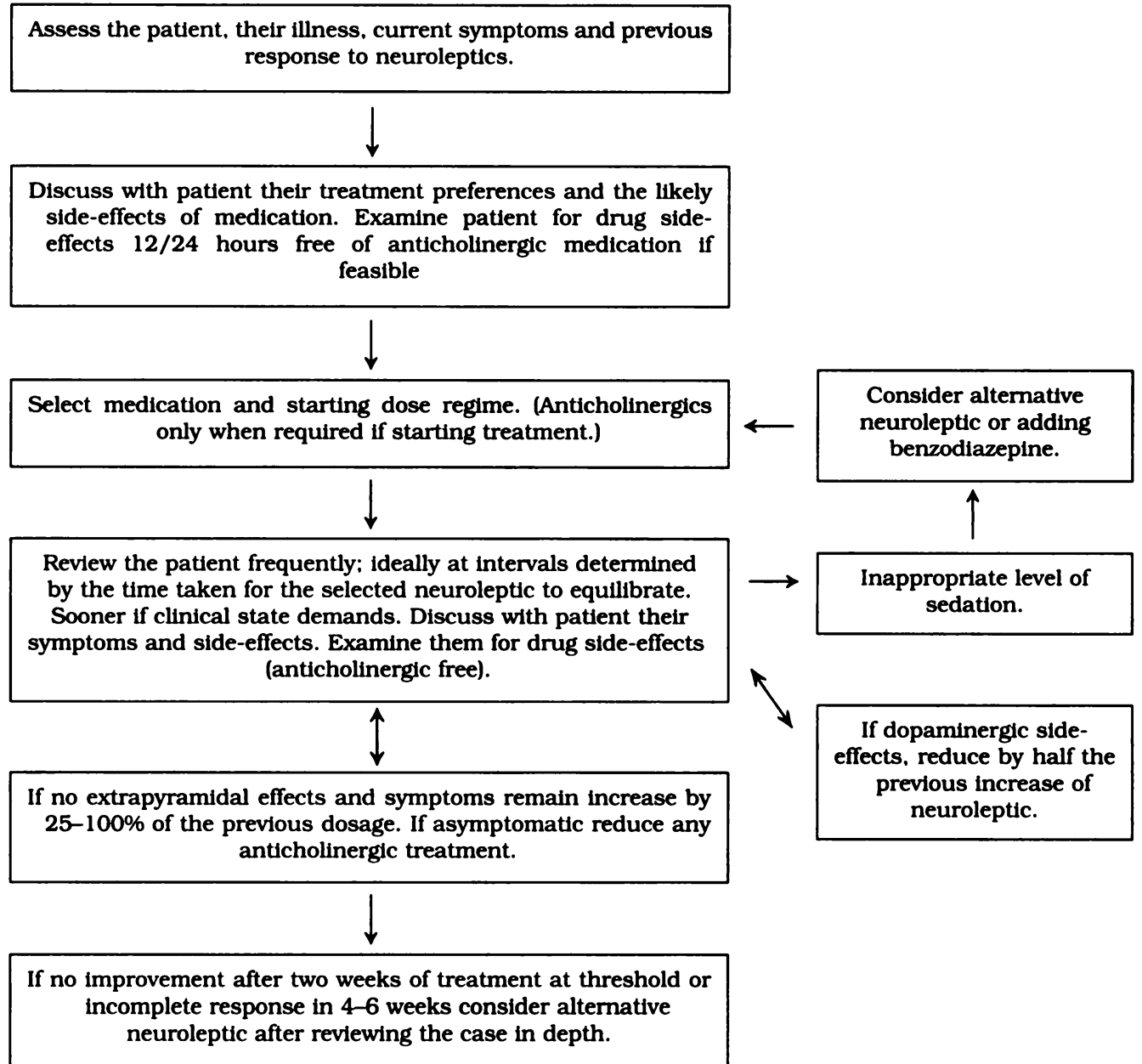

Figure 1. Neuroleptic treatment flow chart: 'The McEvoy Routine' (modified from McEvoy et al, 1986)

Table 2. Depot injections

\begin{tabular}{llll}
\hline & $\begin{array}{l}\text { Average half-life } \\
\text { (days) }\end{array}$ & $\begin{array}{l}\text { Average time to } \\
\text { steady state (weeks) }\end{array}$ & Sedation \\
\hline Flupenthixol decanoate & 17 & 12 & + \\
Fluphenazine decanoate & $6-9$ & $4-6.5$ & ++ \\
Haloperidol decanoate & 12 & 15 & ++ \\
Pipothiazine palmitate & 15 & 11 & + \\
Zuclopenthixol decanoate & 17 & 12 & ++ \\
\hline
\end{tabular}

sedation can either be achieved by swapping to a more sedative drug or adding benzodiazepines (Table 1). The equilibration process is much extended by the use of depot medication (Table 2). With depots it is difficult to judge when to increase the dose in a psychotic person as at the point that their mental state improves a race between neuroleptic metabolism and increasing sensitivity to dopamine blockade may leave a patient above the threshold for weeks or months.

Should a patient obtain considerable but incomplete improvement at 'threshold', using small doses of an anticholinergic drug and staying a little above the 'threshold' may well be the best course. Should one compound fail then the use of a chemically distinct one is indicated, 
but after a number of failures I would suggest that the atypical antipsychotics should be tried.

\section{Neuroleptic threshold determination}

Examination: watch the patient lying or sitting perhaps with shoes and socks removed (to observe restless toes) then rise, walk a short distance, turn, return and stand. Note the patient's spontaneous gestures and facial expression during a brief conversation. Flex and extend the patient's arm irregularly at the elbow and wrist. Note restlessness, increased tone, cogwheel rigidity, stiffness or akinesia (modified from McEvoy et al, 1986).

\section{Pharmacological background}

There are sensible pharmacokinetic reasons for limiting doses of neuroleptics to threshold levels. Extrapyramidal symptoms only occur when 20$30 \%$ of dopamine $\left(D_{2}\right)$ receptors remain unblocked and this level of $\mathrm{D}_{2}$ blockade is also thought to be a crucial element of the antipsychotic mechanism of neuroleptics (Farde et al, 1992). $\mathrm{D}_{2}$ blockade of $70-80 \%$ does not lead to immediate resolution of psychotic symptoms but clinical improvement goes with reductions in the dopamine metabolite homovanillic acid (Pickar et al, 1986), implying reduced dopamine activity which would explain the coincident apparent increased sensitivity to $D_{2}$ blockade (more extrapyramidal side-effects observed on stable neuroleptic dosage; 'neuroleptic threshold' falling).

\section{Clinical impact}

This change in prescribing practice was not arranged as a clinical trial or audit project as I was refining the process as it occurred. The doses of neuroleptic medication were not uniformly low but always closely monitored to ensure no significant side-effects. I hope some readers will feel impelled to use this routine and audit or investigate the results.

Retrospective examination of the length of stay of all patients admitted under my care with a clinical diagnosis of schizophrenia for two consecutive 1 January-30 June periods (one before and the other after the change in practice) did not show any increase in the length of in-patient stays: before, 54 days $(n=17$, range $1-161$, s.e.m. $=12.5)$; after, 51 days $(n=14$, range $4-207$, s.e.m. $=15.6$ ). The discharge medication of the patients changed in the expected manner confirming a real change in practice after the introduction of the schedule: before average daily neuroleptic equivalents $580 \mathrm{mg}$ chlorpromazine ( $n=11$, range 63-2300, s.e.m.=194); after average daily neuroleptic equivalents $420 \mathrm{mg}$ chlorpromazine $(n=12$, range $100-1000$, s.e.m. $=104)$ : before mean 1.5 doses of anti-muscarinic daily ( $n=11$, range $0-3)$; after 1.0 doses $(n=12$, range 0-3). Patients lost for dosage calculation: five details unavailable, two non-compliant with medication, one taking risperidone.

\section{Conclusion}

To subject patients to neuroleptic-induced movement disorders is likely to be seen in the near future as bad practice. The procedure outlined above provides a low risk method of refining the prescription of current neuroleptics. Research in this area should prove very fruitful and would be potentially highly beneficial to clinical practice. perhaps even allowing the rehabilitation of neuroleptic compounds following the potentially misleading recommendations from fixed-dose schedule trials.

\section{Acknowledgement}

I wish to thank Christine Main. Chief Pharmacist, for her help with this manuscript.

\section{References}

FARDE, L., NORDSTROM, A.-L., Wiesel, F.-A., et al (1992) Positron emission tomographic analysis of central $D_{1}$ and $D_{2}$ dopamine receptor occupancy in patients treated with classical neuroleptics and clozapine: relation to extrapyramidal side effects. Archives of General Psychitry. 49, 538-544.

HILTON, T., TAYLOR, D. \& ABEL. K. (1996) Which dose of haloperidol? Psychiatric Bulletin. 20, 359-362.

McEvoy, J. P., STILLER, R. L. \& FARR, R. (1986) Plasma haloperidol levels drawn at neuroleptic threshold doses: A pilot study. Journal of Clinical Pharmacology, 6, 133138.

-. Hogarty, G. E. \& Steingard, S. (1991) Optimal dose of neuroleptic in acute schizophrenia. Archives of General Psychiatry. 48, 739-745.

Pickar, D. LABARCA, R. DORAN, A. R. et al (1986) Longitudinal measurement of plasma homovanillic acid levels in schizophrenic patients: correlation with psychosis and response to neuroleptic treatment. Archives of General Psychiatry. 43, 669-676.

Thompson. C. (1994) The use of high-dose antipsychotic medication. Consensus statement. British Joumal of Psychiatry, 164. 448-458.

G. F. Searle, Consultant Psychiatrist, Dorset Healthcare NHS Trust, King's Park Unit, Gloucester Road, Boscombe, Bournemouth, BH7 GJE 